\title{
An Enhanced Communication Model
}

\author{
Per Flensburg. University West, Sweden. per.flensburg@hv.se
}

\begin{abstract}
The concept of information is often taken for more or less granted in research about information systems. This paper introduces a model starting with Shannon and Weaver data transmission model and ends with knowledge transfer between individual persons. The model is in fact an enhanced communication model giving a framework for discussing problems in the communication process. A specific feature of the model is the aim for providing design guidelines in designing the communication process. The article ends with identifying a need for develop the model further to incorporate also communication within and between organisations of different kinds.
\end{abstract}

Key words: Information, communication, communication model, knowledge.

\section{INTRODUCTION}

To quote a famous Swedish Informatics professor: "Already in the sixties I realised that data and information was different!" The professor I refer to is of course Börje Langefors and it was he who actually triggered my interest in this area. However, at that time I did not agree with the Famous Icon! I claimed that Börje was talking about knowledge and not about information; that he made no distinction between them. However, as young Ph D student, my remarks were of little interest. But in my teaching I developed a model of data, information and knowledge and several hundred Swedish students have more or less willingly tried to understand it. When I in the early 2000 began thinking about network economy and systems integration the model was refined with something I called "content". Preparing for HCC7, in Sep 2006, I saw the similarities 
between my ideas about data, information, content and knowledge and the communication process. I presented the main idea at the conference - it was not in the proceedings - and many people liked it. So, here it comes. Enjoy!

\section{THE PROBLEM OF TRANSFERRING KNOWLEDGE BETWEEN HUMANS}

Shannon and Weaver (Shannon and Weaver, 1949) introduced their model of a communication system in 1949 (fig 1). This is however, a model of signal processing. They did not address the question of the content that was transferred; they only proved that it can be described as transfer of a bitstream.

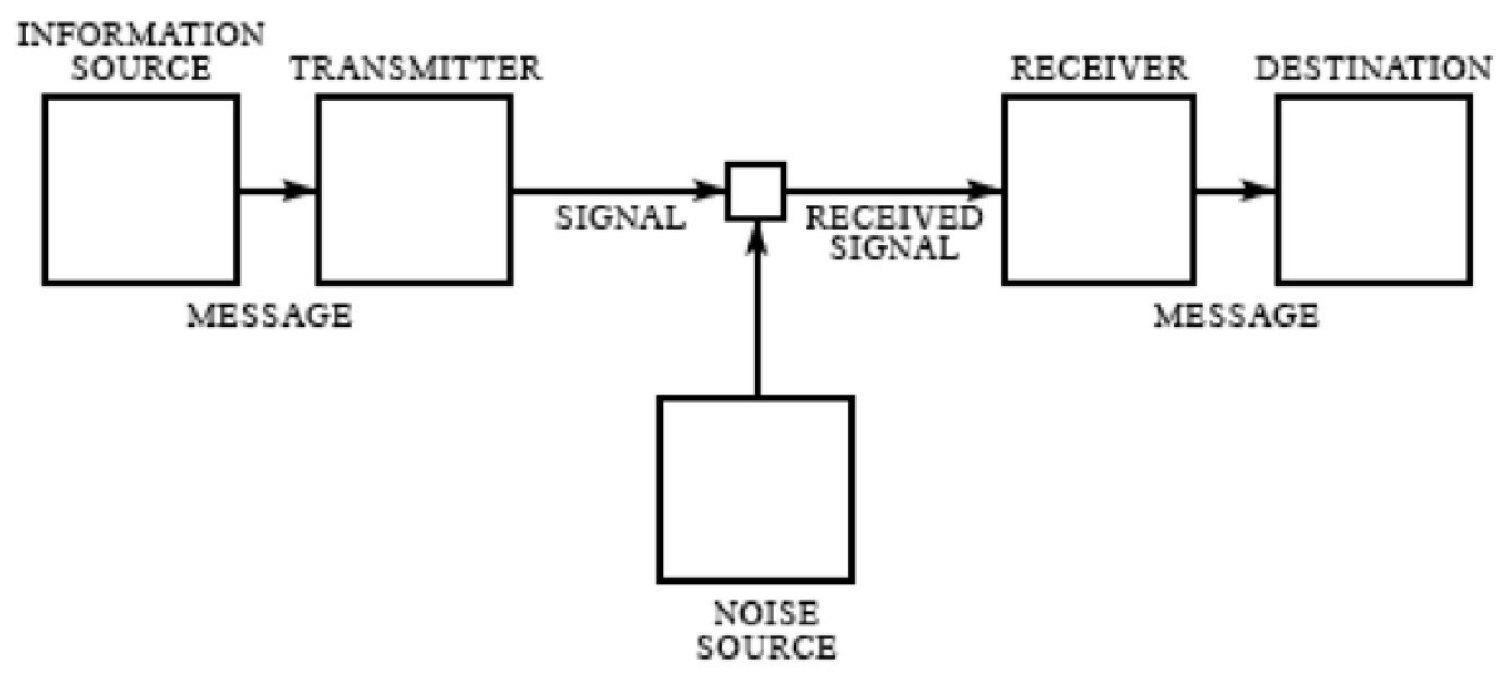

Figure 1. Schematic diagram of a general communication system

In this paper I will develop Shannon's model further up to knowledge transfer and then, from a theoretical perspective, address the question of knowledge transfer between organisations. So let us start our discussion by simplifying Shannon's model as it is seen to the left. A bitstream is transferred and there are some noise coming in. Shannon showed that corrections can be done using redundancy and by calculating checksums. By using the appropriate checksum algorithm we can even correct the transfer and thus be sure the send bitstream corresponds to the received. But Shannon does not say anything about the content; about what is transferred. 


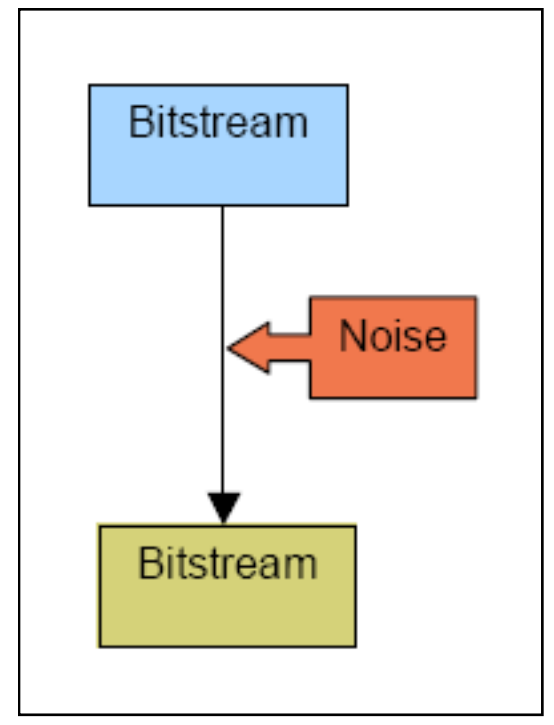

Figure 2. Bitstream

Anyone who has dealt with data transmission knows that you have to know something about the format and type of data that are to be transferred. First you have to know if it is data or a program. If it is a program you have to know if the transfer is binary or hexadecimal and later on of course, if it is a program for a PC, Mac or Linuxcomputer. If it is data you transfer, you must know something about the type (text, picture, audio, video or something else). For each type you must know exactly what type it is (7-bits ASCI-text, JPEG-picture, mp3-file or a divX-movie etc.). In short, you have to know the format of the bitstream in order to put the 1:s and 0:s together in a sensible way. The sender and the receiver must also have the same format. Technically you can execute a picture as a program, but the result is likely to be need for restart of the computer. Identity of the format is secured by using certain standardised format recognised by the file suffix. For instance a file with the suffix .jpg is to be treated as a picture in jpeg-format. In this case the noise (or rather insecurity) in the match of the format is reduced by heavy standardisation. So in short: Bitstream + format $=$ data (fig 3 ).

Let us now for simplicity restrict our reasoning to text transfers. The principles can be applied for other types of transfers as well, but it is simpler to describe them for texts. 


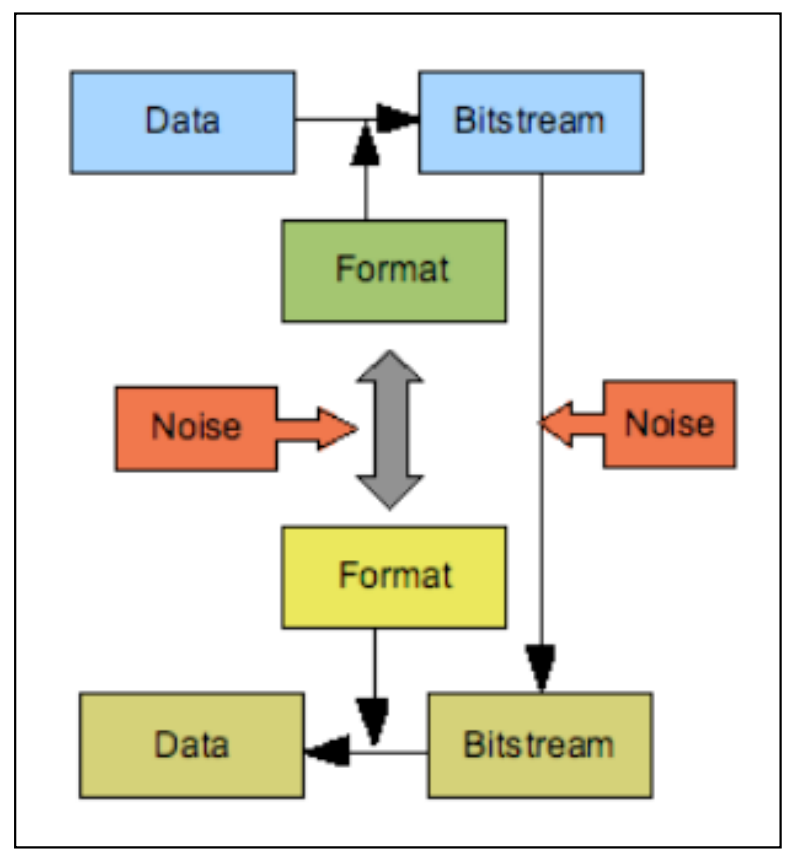

Figure 3. Data

Up to now we have transferred characters. In order for them to make sense we first have to put them together in words. We thus add structure in order to form words. The noise is reduced by using a specific vocabulary that is a predefined set of allowed words. If we are transferring free text, we have principally all words in the actual language available. But we have to say if it is a free text and in which language. If we transfer some more structured data, such for instance an instance of a database record, the vocabulary are considerably restricted, but on the other hand we can more efficiently secure the same data are transferred. In short: Data + structure $=$ Information $($ fig 4$)$.

In the case of transfer between two (or more) data bases the data can be seen as organised in tables and we have to know the headings in the columns in order for the transfer to succeed. The same goes for free text, we must put the words in correct order according to a grammar in order for the information to be interpreted in the intended way. We thus have to add meta-data in order for the information to be transformed to content, a concept I think is needed for introducing some ordered information. The noise in this case is reduced by explicit descriptions of the meta-data or use of a common everyday grammar. However it not possibly to ensure a perfect match, this is especially relevant for free text transfer. The grammar of our everyday language is not completely formalised; a lot of the meaning is implicit and have to be concluded from the text around. Redundant information as questioning and explanations might be also needed. So in short: Information + Meta-data = Content. (fig 5). 


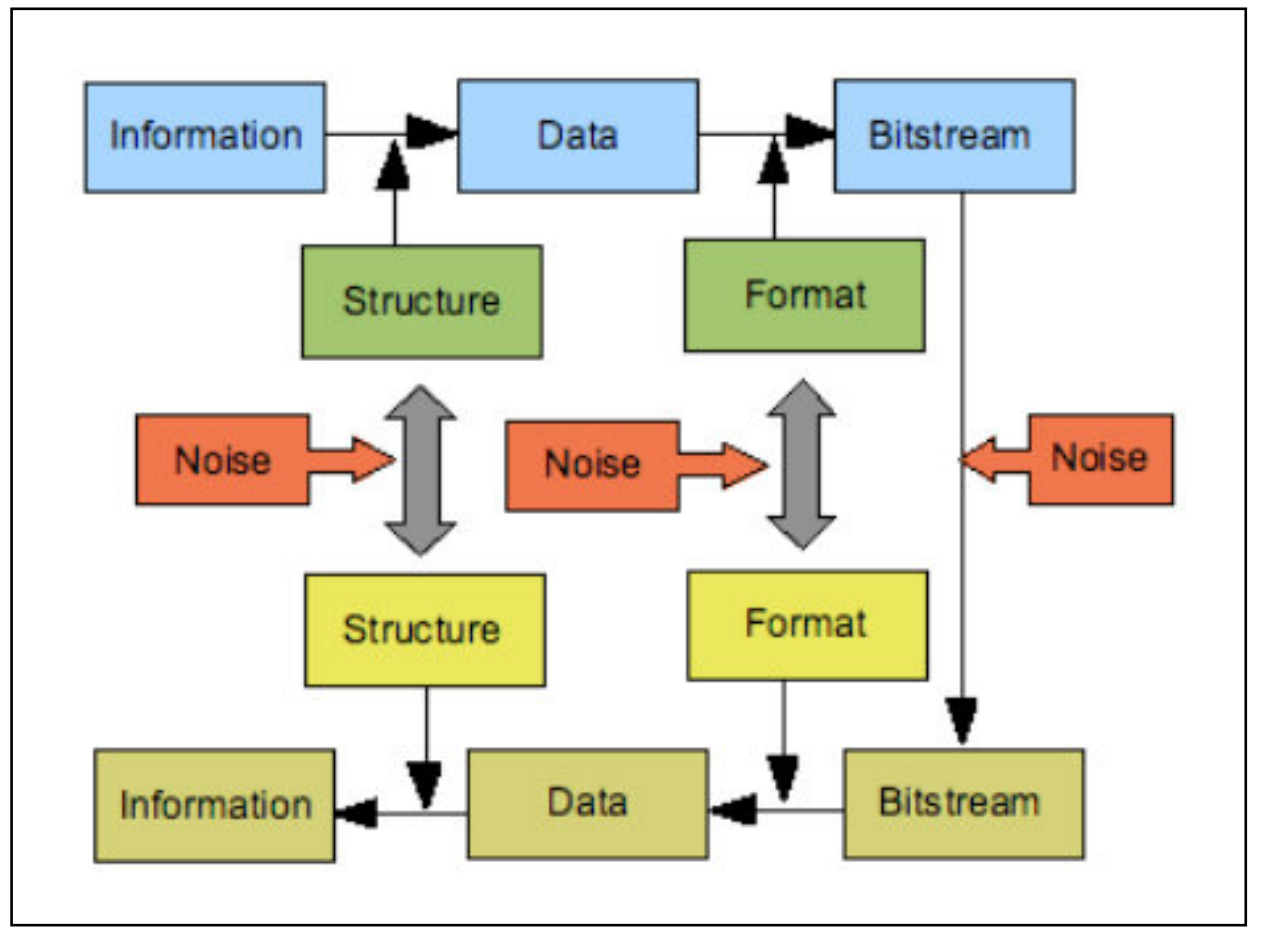

Figure 4. Information

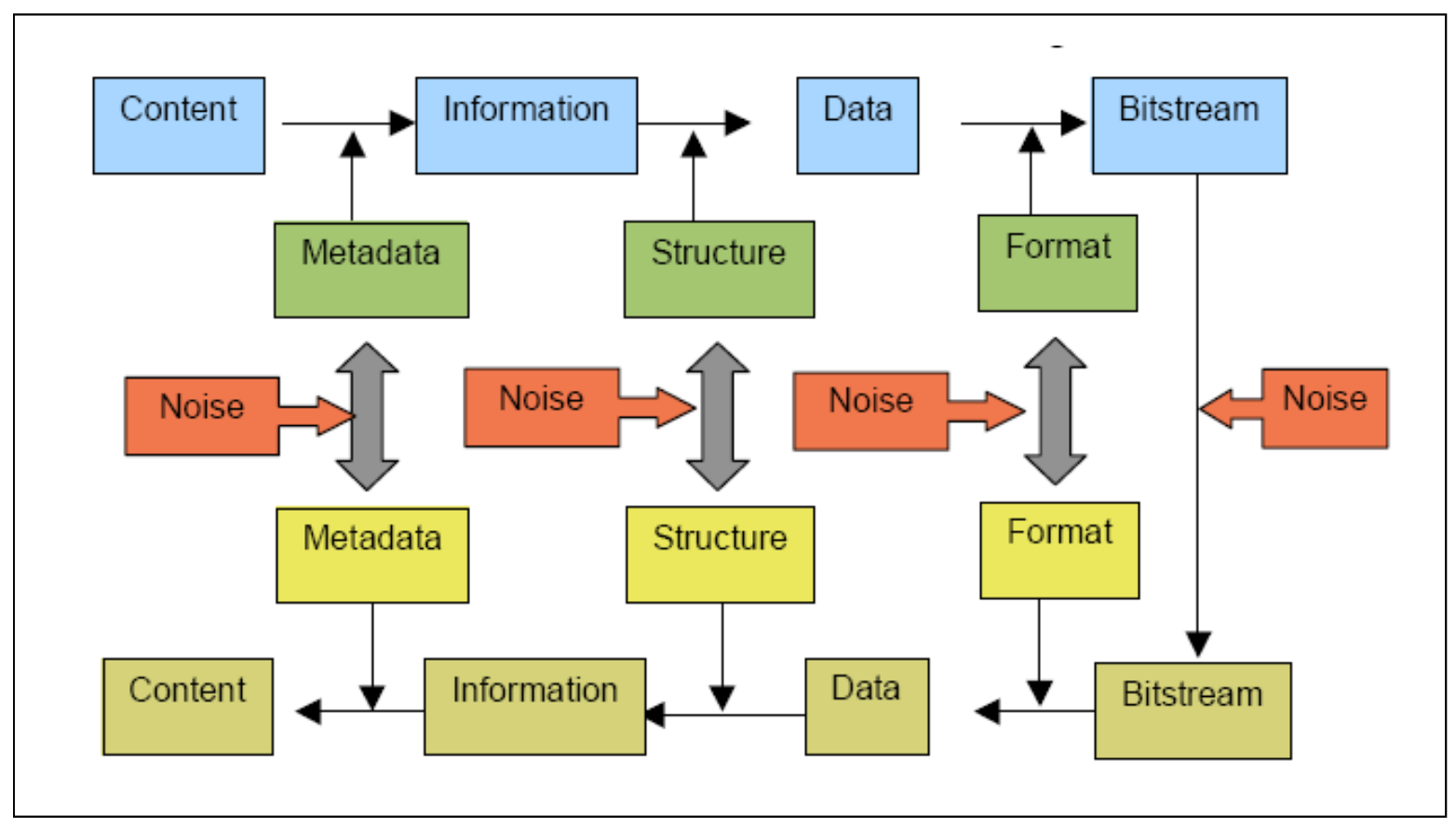

Figure 5. Content 
Now we can proceed to the last step and talk about knowledge transfer. In order for the content to be possible to interpret as knowledge for a human being, a context is needed. The context provides the background for the humans to understand the meaning of the content. It is to be noted that only human beings can have knowledge. No humans have exactly the same context so much effort is needed in order to secure that the relevant context are the same. This is to be discussed later, but for now we note that everybody who has transcribed an interview, know that most of the time is used for ensure that the receiver has interpreted the content in the intended way and they share the same context. In short: Content + Context $=$ Knowledge (fig 6).

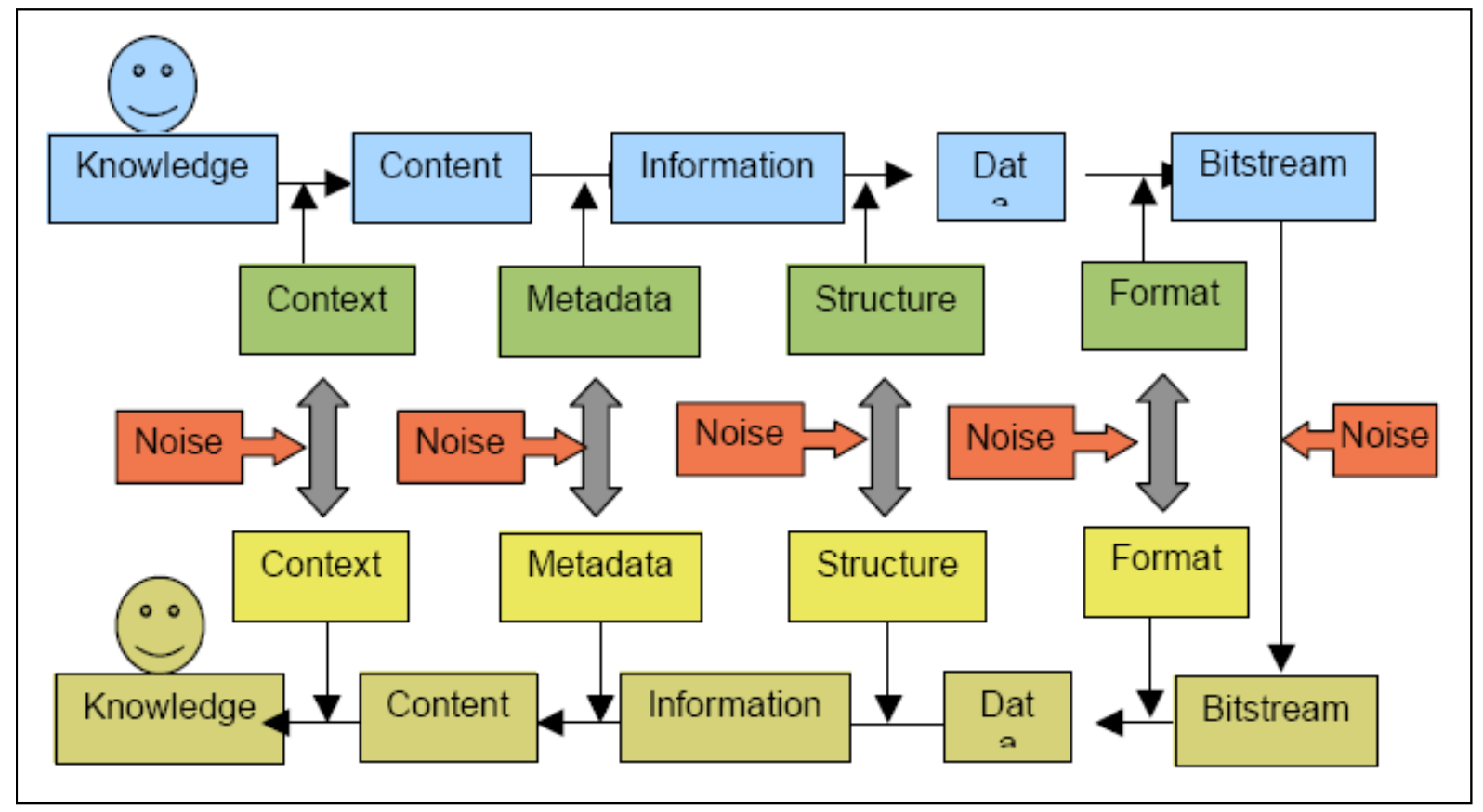

Figure 6. Knowledge

The concept "knowledge transfer" seems to be little odd at the first glance. It associates to something mechanical and not something human. One can ask what is the difference between "knowledge transfer" and "teaching"? Or "learning"? In my opinion, "knowledge transfer" is about the meaning of the content while "teaching" and "learning" is about the process of this transfer. "Teaching" and "learning" often have another purposes, you are supposed to change attitude, or opinion just by being taught. I will leave this process out of the scope of this paper, since there are numerous articles and books written about it and instead discuss the concept of "knowledge". 


\section{KNOWLEDGE}

The difference between "content" and "knowledge" might be unclear and one might argue that "content" is also a type of knowledge. According to my definition "content" is achieved by adding meta-data to "information". Thus, all what is needed is contained in this meta-data. But what is meta-data? Isn't metadata also a kind of knowledge and does not meta-data require its own context? This is correct, but the context of the meta-data is a simpler context and partly formalised. Principally content can be transferred between computers, provided they have the same meta-data. However, this is not possible for knowledge, since it requires a creative act in the interpretation.

The model above deals with a specific type of knowledge, namely knowledge that can be expressed as content in a context. It does not deal with "skill" or "wisdom" or "tacit knowledge". All these aspects seem however to be embedded in the context and when the context match and the content match, then we have a knowledge match. But how is this match achieved? At first glance it might seem almost impossible, since every human has his or her own context, made up of all our experiences during our lifetime. But experience shows it is possible for people to understand each other, it is possible to exchange knowledge. Despite the fact we have no exact match in context we have enough in common to create an understanding and thus knowledge. The word "create" is deliberately chosen, since I mean new knowledge is created when you understand something you did not understood before. That's why knowledge has something to do with creativity and as Churchman argues, creativity is an exclusive human behaviour (Churchman, 1971).

The key for understanding is thus to share enough context. If we study how people in practice talk to each other we see lots of efforts spend in order to make the other part understand. An exact transcript of an interview, reveals, as said before, how much redundancy is used and if the interview is also videotaped we see the body language add to this understanding. The aim is to achieve a shared context enough for understanding and the communication goes back and forth, since the speaker is usually very sensitive for the listeners' reaction. Every lecturer with some experience knows when it is time for a break in the lecture room! So when we talk it is interaction and not only transfer.

In speech, the understanding is achieved by redundancy and by feed-back from the listener. But often speech is not possible and how is it then done? In traditional information systems we assume the system is the same and this assumption is often implicit, as Langefors points out in his elementary message (Langefors B, 1966). As long as we talk within one or 
two single companies it might work, but when we have a global information system, working in hundreds of companies and supporting a complex business process using hundreds of different systems, we can not rely upon one single system definition.

As indicated above, up to the level of "content" the transfer process is fairly formalised and in practice different versions of web-services is used. However, they assume all a common ontology, i.e. meaning of the concepts used. This is achieved by using standard ontologies and standard vocabularies. (Fensel et al., 2000). But it goes only up to the content level, when it comes to knowledge it is not enough. In modern e-business and other ephenomenon, it is many times enough, since agreements have been made to follow a certain business process with predefined ontology (Schoening J, 2003). But in order to make a correct choice the user must know the meaning or in other words: Share the context of the business process to such an extent that knowledge is possible for him or her!

This is even more important when the process is not a business process but instead for instance a treatment process at a hospital or an issue in a public government. There the metadata is hard to formalise and the result is often narrowminded bureaucracy leading to unacceptable results.

The problem now narrows down to: How can people ensure they share the same context to such a degree that understanding is possible? This is needed for the business processes (including public business) to be performed the intended way. I think storytelling is the answer. When we try to explain difficult things we often use an example, i.e. a story. When we read a good book, we get a view of the situation at that place and that time and create a context. But how can storytelling be used in businesses processes? How can the need for exact descriptions be satisfied in a fuzzy story? It can't, the story provides a background, a rich picture (Checkland, 1981) against which we interpret the content provided. The story needs also to be read and understood only once, since after that it is a known story. The idea is that when a person engages in a business process (n.b. including public business!) for the first time he or she reads the story behind the process and then hopefully understands the basic idea.

How is this story constructed? It should describe the activities in the process chain, it should describe items involved and it should describe complications that can occur and how these should be dealt with. All in a nice readable form! So new experts are needed: The business process storyteller, who tells the stories behind the process. This person must have the skill of a story-teller, be creative and also to some extent understand information systems 
and their role in the modern, networked organisations. But so far this expert has not been seen in reality.

\section{PROS AND CONS WITH THE MODEL}

The model is so far a theoretical construct. Further on, it provides a vocabulary for discussing certain issues about communication and is thus more like a tool for the scientist than for use in for instance practical systems development. The model is not operationalised, in fact I don't think that would be a good idea, since the power of the model is to provide a framework for discussions, not a fixed solution. The strength of the framework is the identification of several similar steps in the communication process which can be treated in a rather coherent way. However, this might lead to a believe that all steps are possible to formalise, which is not the case. I also think it is highly unbelievable that organizations employ a storyteller for telling stories about their business processes. Very few managers will have such a creativeness and boldness. In public processes such as in e-governence the transactions are much more complicated than the business transactions covered in traditional business processes. Also the need for correct interpretation of a public business transaction can be a matter of life or death as for instance in the health care system. Thus a correct interpretation is essential.

\section{FURTHER RESEARCH}

So far I have only talked about knowledge transfer between single persons. But the context used in the presentation is business processes in both public and private companies. Hence, it would be interesting to enhance the model to cover also organisations and thus be able to discuss knowledge transfer between organisations. Since the model ends in storytelling and I claim story-telling is the way to transfer knowledge the model ought to be described in this way, as a story. Also the mechanisms of story-telling ought to be explored more. I guess literature science can provide some good ideas for this.

\section{OTHER MODELS}

There are of course other models of communication available, both earlier than Shannon \& Weaver and later. One of the earliest is Aristotles simple linear model. In his Rhetoric (Aristotle, 350 B C), Aristotle tells us that we must consider three elements in communication: 
- the speaker

- the speech

- the audience

It is a simple linear model and very obvious. In this paper I focus on the speech, but all three elements are tightly connected. Another interesting model is the model of Laswell (Laswell H D, 1948) which is often described as in fig 7.

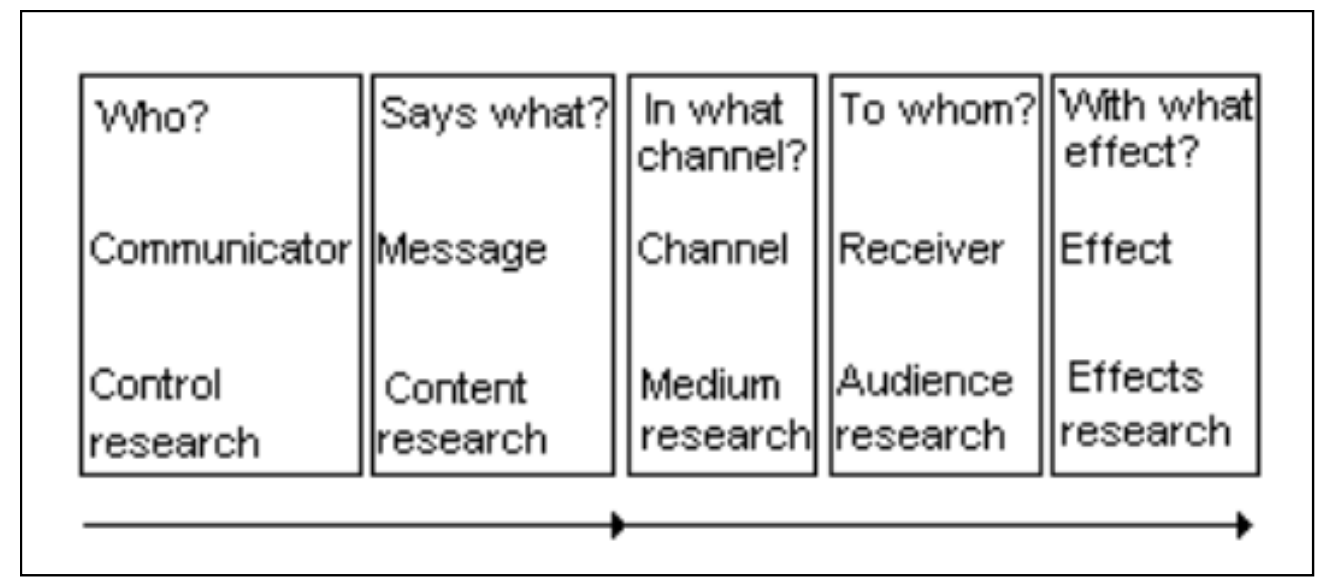

Figure 7. Lasswell's model

It is to be noted that it was published before and had in accordance with Aristotle(Aristotle, 350 B C) its base in politics and mass communication. I have myself and unknowing of Laswell, developed a similar model for systems analysis and ontology generation, the Socrates model (Flensburg, 1988). It has also been used in an EU-project for ontology generation in the automotive industry (Flensburg P, 2004).

A more elaborated model is presented in (Berlo D, 1960). It is also a linear transmission model based upon the steps Source, Message, Channel and Receiver, but each step is more elaborated (fig 8). In fact, there are resemblances to the model I suggest; even some of the concepts are the same. However, Berlo does not distinguish between bitstream, data and information; they are all imbedded in the code. Further on, he does not introduce the concept of meta-data. 


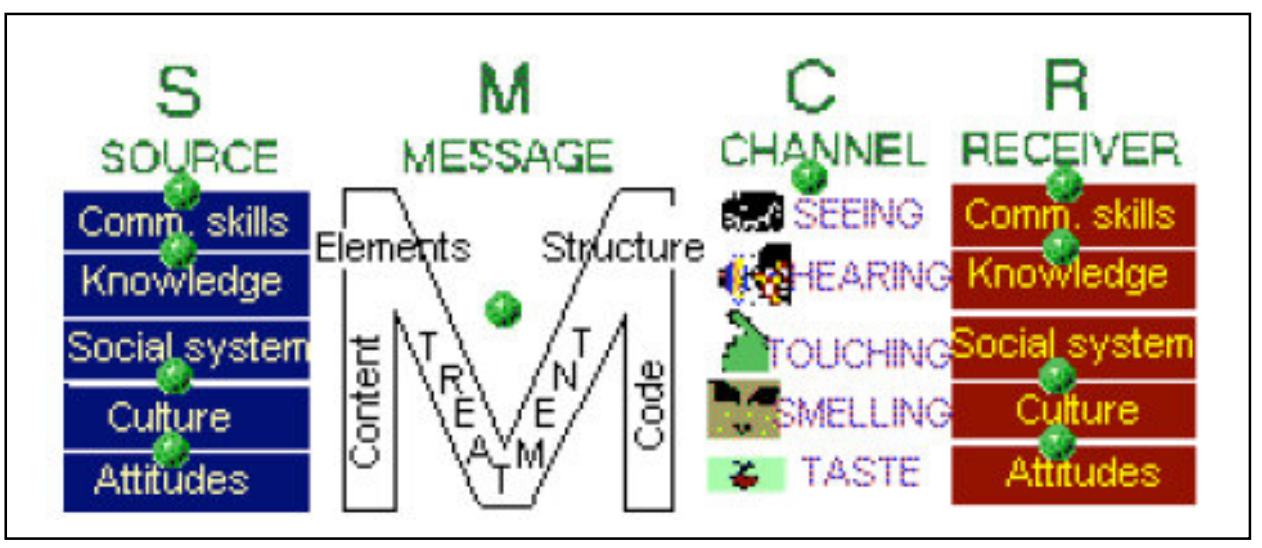

Figure 8 . The model of Berlo

The transmission models have received critique for not taking the meaning, intention, context of the communication into account as well as the channel and the relations between the sender and receiver. Much of the critique can be traced to semiotics and similar linguistic approaches (Saussure de, 1971). Fish (Fish S, 1980), who is a literature scientist rejects the text's independence as a repository of meaning. He emphasizes that meaning is not inherent waiting to be 'transmitted' to more or less passive 'receivers'. Rather, the reader's active construction of meaning is so central that it might even be more accurate to speak of writing than of reading.

Berlo (Berlo D, 1960) also emphasizes the meaning. In short he says:

- Meanings are in people.

- Communication does not consist of the transmission of meanings, but of the transmission of messages.

- Meanings are not in the message; they are in the message-users.

- Words do not mean at all; only people mean.

- People can have similar meanings only to the extent that they have had, or can anticipate having, similar experiences.

- Meanings are never fixed; as experience changes, so meanings change.

- No two people can have exactly the same meaning for anything. 
The models I have described so far are quite old, but they are well recognized within communication science. The main difference, as I perceive it, is my focus on what is communicated and their focus on the communication process. According to both Fish (ibid) and Berlo (ibid) the receiver has a great role, but I think also the sender has some responsibility to find a suitable form, structure and context in order to make the meaning of the message as easy to understand as possible.

\section{REFERENCES}

ARISTOTLE (350 B C): Rethorics, Athens.

BERLO, D. (1960): The Process of Communication, Holt, Rinehart and Winston Inc., New York, NY.

CHECKLAND, P. (1981): Systems thinking, systems practice, John Wiley \& Sons, London, UK.

CHURCHMAN, C. W. (1971): Design of inquiring systems, Basic Books, New York.

FENSEL, D.; HARMELEN, F.; KLEIN, M.; AKKERMANS, H. (2000): "On-ToKnowledge: Ontology-based Tools for Knowledge Management", In Proceedings of the eBusiness and eWork 2000 (EMMSEC 2000) Conference, Madrid, Spain.

FISH, S. (1980): Is There a Text in This Class?: The Authority of Interpretive Communities, Harvard University Press, Cambridge, Mass.

FLENSBURG, P. (1988): Systemutveckling med människan i centrum, Lund, Studentlitteratur.

FLENSBURG, P. (2004): "Generation of ontologies for workflows", in Learn IT, Know IT, Move IT - IRIS 27, Flensburg, P. \& Ihlstrom (Eds.), Falkenberg, Sweden.

LANGEFORS, B: (1966): Theoretical Analysis of Information systems, I \& II, Lund, Studentlitteratur.

LASWELL, H. D. (1948): "The structure and function of communication in society", in The communication of ideas, L., B. (Ed.), Harper, New York, NY.

SAUSSURE DE, F. (1971): Cours de Linguistique Générale, Paris, Payot.

SCHOENING, J. (2003): EEE P1600.1, Standard Upper Ontology Working Group (SUO WG), Home Page. IEEE. 
SHANNON, C. E. \& WEAVER, W. (1949): The mathematical theory of communication, Urbana,University of Illinois Press. 